\title{
Article \\ Determination of Antimicrobial and Antibiofilm Activity of Combined LVX and AMP Impregnated in p(HEMA) Hydrogel
}

\author{
Ola Tarawneh*(D), Wasan Alwahsh, Hassan Abul-Futouh (D, Luma A. Al-Samad, Lama Hamadneh (D), \\ Hadeel Abu Mahfouz and Abdulqader Fadhil Abed
}

Faculty of Pharmacy, Al-Zaytoonah University of Jordan, Amman 11733, Jordan; wasanibrahimalwahsh@gmail.com (W.A.); h.abulfutouh@zuj.edu.jo (H.A.-F.); lamaadel@zuj.edu.jo (L.A.A.-S.); lama.hamadneh@zuj.edu.jo (L.H.); hadeelaabumahfouz@gmail.com (H.A.M.); abdulqader.fadhil10@gmail.com (A.F.A.)

* Correspondence: ola.tarawneh@zuj.edu.jo

check for

updates

Citation: Tarawneh, O.; Alwahsh, W.; Abul-Futouh, H.; Al-Samad, L.A.; Hamadneh, L.; Abu Mahfouz, H.; Fadhil Abed, A. Determination of Antimicrobial and Antibiofilm Activity of Combined LVX and AMP Impregnated in p(HEMA) Hydrogel. Appl. Sci. 2021, 11, 8345. https:// doi.org/10.3390/app11188345

Academic Editor: Giacomo Dacarro

Received: 25 July 2021

Accepted: 6 September 2021

Published: 8 September 2021

Publisher's Note: MDPI stays neutral with regard to jurisdictional claims in published maps and institutional affiliations.

Copyright: (c) 2021 by the authors. Licensee MDPI, Basel, Switzerland. This article is an open access article distributed under the terms and conditions of the Creative Commons Attribution (CC BY) license (https:/ / creativecommons.org/licenses/by/ $4.0 /)$.
Abstract: Catheter-associated urinary tract infections (CAUTIs) are nosocomial infections, causing more than one million cases per year. CAUTIs cause serious health issues; in addition, the cost of replacement of the device constrains the employment of urological devices. Therefore, there is an urgent need to develop novel biomaterials for use in catheters. In this study, poly hydroxyethylmethacrylate p(HEMA) and drugs-loaded p(HEMA) with ampicillin trihydrate (AMP), levofloxacin (LVX), and drug combinations were prepared using free radical polymerization. The characterization of the dried films included the determination of glass transition temperature ( $\mathrm{Tg}$ ), ultimate tensile strength, elongation percentage, and Young's modulus. Formulation toxicity, antimicrobial activity, and biofilm-formation ability were tested. Decreases in Tg value, U.T.S., and Young's modulus, and an increase in elongation percentage were observed in AMP-loaded p(HEMA). Different ratios of drug combinations increased the Tg values. The films exhibited a cell viability higher than $80 \%$ on HEK 293 cells. Antimicrobial activity increased when p(HEMA) was loaded with LVX or a combination of LVX and AMP. Biofilm-forming ability reduced after the addition of antimicrobial agents to the films. p(HEMA) impregnated with AMP, LVX, and drug combinations showed significantly increased antimicrobial activity and decreased biofilm-forming ability compared with p(HEMA), in addition to the effects on (HEMA) mechanical properties.

Keywords: poly hydroxyethyl-methacrylate p(HEMA); levofloxacin; ampicillin trihydrate; $\mathrm{pH}$ sensitive hydrogels; microbial biofilm; antimicrobial activity

\section{Introduction}

The insertion of medical devices such as urinary catheters and stents is often reported to increase the risk of developing bladder infections [1,2]. Bacteria can colonize the outer surface of the catheter and lead to bacterial escape through the bladder and cause extraluminal infection. Bacterial adhesion is the rate-limiting step of infection development on the surface of implants [3,4]. Moreover, it initiates the formation of infections via enhancing the attachment and colonization of bacteria in the host cells [5]. Bacterial adhesion on the material surface is governed by reversible weak forces such as van der Waals forces or electrostatic effects and by irreversible strong and long-lasting bonds such as covalent bonds [2,6]. Microorganisms can aggregate irreversibly on the surface of the urinary devices. This leads to the formation of biofilm, which is a complex structure composed of glycocalyx, made of carbohydrates, proteins, and nucleic acid [7]. Biofilms maximize the resistance of microorganisms against microbicide by 10-1000 times compared with their planktonic complement, and hence make the treatments more difficult, necessitating the replacement of the medical device with a new one [8].

Several antimicrobial agents are used to treat urinary tract infections caused by catheterization: ampicillin (AMP) [9] and levofloxacin (LVX) [10]. Both are documented as 
broad-spectrum antimicrobial agents used for the treatment of complicated urinary tract infections [11] with a respectable spectrum of activity against many Gram-positive and Gram-negative bacteria [12].

$\mathrm{pH}$-responsive hydrogels are stimuli-responsive polymers responding to $\mathrm{pH}$ changes through structural and property modifications, such as surface activity, chain conformation, and solubility $[13,14]$. Therefore, drug-loaded $\mathrm{pH}$-responsive hydrogels have been organized as delivery systems, such as anti-bacterial agents for $\mathrm{pH}$-tunable drug release [15].

Poly hydroxyethyl-methacrylate $\mathrm{p}$ (HEMA) is a $\mathrm{pH}$-sensitive polymer, containing anionic hydrogel with a primary alcohol [16] that has hydrophilic and lipophilic moieties; it is non-toxic, transparent, and insoluble in water $[17,18]$. Furthermore, p(HEMA) offers stable mechanical properties [19]. p(HEMA) is reported to be prepared by additional polymerization (free radical polymerization) of free radical initiator (2.2-azobis (2-methylpropionitrile)) [20]. p(HEMA) has been used in various applications such as contact lenses, drug delivery vehicles, tissue engineering scaffolds, and in urinary catheters [21-23].

The objective of the study was to develop a coating layer for the urological devices composed of poly hydroxyethyl-methacrylate $\mathrm{p}$ (HEMA). $\mathrm{p}$ (HEMA) loaded with ampicillin trihydrate (AMP), levofloxacin (LVX), and equal and different ratios of the drug combinations. This was subsequently followed by an examination of the glass transition temperature, tensile properties, cell line toxicity, antimicrobial activity, and biofilm-formation ability.

\section{Materials and Methods}

\subsection{Materials}

Levofloxacin (MW $361.4 \mathrm{~g} / \mathrm{mol}$ ) was kindly donated by Dar Al Dawa Pharmaceuticals (Amman, Jordan). Ampicillin trihydrate (MW $403.5 \mathrm{~g} / \mathrm{mol}$ ) was from Ibn Hayyan Pharmaceuticals (Amman, Jordan). Bacterial cells were obtained from American Type Culture Collection (ATCC) (Manassas, VA, USA); Escherichia coli (E. coli ATCC 8739, Staphylococcus aureus (S. aureus) ATCC 6538, and Pseudomonas aeruginosa (P. aeruginosa) ATCC 9027). 2hydroxyethyl methacrylate (2-HEMA) (MW $130.14 \mathrm{~g} / \mathrm{mol}$ ), ethylene glycol di methacrylate (MW 198.22 g/mol), and 2.2-azobis (2-methyl-propionitrile) (AIBAN) (MW $164.21 \mathrm{~g} / \mathrm{mol}$ ) were obtained from Sigma-Aldrich (Munich, Germany). Müller Hinton agar (MHA) and broth (MHB) were obtained from HIMEDIA (Mumbai, India). Brain heart infusion broth was purchased from biolab (Budapest, Hungary). Human embryonic kidney (HEK 293) cell line was from ATCC (Manassas, VA, USA). T75 flasks were from SPL Life Sciences Co. (Gyeonggi-do, Korea). All cell culture reagents were purchased from EuroClone S.p.A., Via Figino, Italy.

\subsection{Preparation of $p(H E M A)$ Hydrogel Films}

Poly hydroxyethyl-methacrylate p(HEMA) films were synthesized as described by Irwin et al. [24], with modification. Ethylene glycol-dimethacrylate (EGDMA, 1\% w/w) and 2,2' azobisisobutyronitrile (AIBN, $1 \% w / w$ ) (cross-linker and initiator, respectively) were mixed at $20{ }^{\circ} \mathrm{C}$ with 2-hydroxyethylmethacrylate (2-HEMA, $\left.98 \% w / w\right)$ by stirring. The resulting $10 \mathrm{~g}$ mixture was injected slowly into molds, (the mold was separated with medical-grade silicone tubing with a lumen diameter of $3 \mathrm{~mm}$ and wall thickness of $0.18 \mathrm{~mm}$, clamped using spring clips). The mixture was left in an oven to allow polymerization at $60^{\circ} \mathrm{C}$ for $18 \mathrm{~h}$. The formed film was soaked for one week in distilled water to remove unreacted monomers, with the soaking medium refreshed daily (absorbance of acrylate was measured daily at $220 \mathrm{~nm}$ to ensure the unreacted monomers were removed). When the measured absorbance of the soaking medium was zero, the film was left to dry in an oven at $30^{\circ} \mathrm{C}$ and weighed daily until a constant weight was obtained [24]. The same procedure was carried out for the preparation of $\mathrm{p}$ (HEMA) impregnated with antimicrobial agents, taking into consideration that the total weight of the mixture was $10 \mathrm{~g}$ and the loaded drug was $0.5 \%(w / w)$, as listed in Table 1 . 
Table 1. Formulations, components and ratios of the prepared hydrogel films.

\begin{tabular}{ccc}
\hline Formulation & Antimicrobial Agent (g) & 2-HEMA (g) \\
\hline F1 (control) & 0.05 AMP & 9.8 \\
F2 & 0.05 LVX & 9.75 \\
F3 & AMP: LVX (1:1) & 9.75 \\
F4 & $0.025: 0.025$ & 9.75 \\
& AMP: LVX (3:1) & \\
F5 & $0.0375: 0.0125$ & 9.75 \\
& AMP: LVX (1:3) & 9.75 \\
F6 & $0.0125: 0.0375$ & \\
\hline
\end{tabular}

\subsection{Determination of Glass Transition Temperature}

AQ800 DMTA (TA, NC, USA) was used to detect the glass transition $\left(\mathrm{T}_{g}\right)$ of the dried films. The experiment was conducted in tensile mode at an oscillatory frequency of $1 \mathrm{~Hz}$ and a heating rate of $3{ }^{\circ} \mathrm{C} \mathrm{min}-1$ in a temperature range of 35 to $160^{\circ} \mathrm{C}$. Dried films (number of replicates, $n=3$ ) were cut into rectangular forms ( $30 \mathrm{~mm}$ length, $10 \mathrm{~mm}$ width, and $0.79 \mathrm{~mm}$ thickness measured using a digital caliper). The $\mathrm{T}_{g}$ was determined from the peak of $\tan \delta$ [25]. Tan $\delta$ is defined as the ratio of loss to storage modulus $\left(\tan \delta=E^{\prime \prime} / E^{\prime}\right)$ [26].

\subsection{Mechanical Properties}

Mechanical properties representing ultimate tensile strength (U.T.S.), elongation percent, and Young's modulus of the dried films were calculated from a TA-XT plus Texture Analyzer (Stable Micro Systems) [27]. Dried films (30 mm length $\times 10 \mathrm{~mm}$ width; number of replicates, $n=5$ ) were clamped between the static and moveable grips, ensuring that the length of the films below stress was constant $(20 \mathrm{~mm})$. The upper clamp was elevated at a fixed rate $\left(0.5 \mathrm{~mm} \mathrm{~s}^{-1}\right)$ until the film fractured. From the resulting stress-strain plot, the U.T.S., percent elongation at the breakpoint, and Young's modulus were calculated [28].

\subsection{Cytotoxity Evaluation of $p(H E M A)$ Hydrogel Formulations}

An MTT (3-(4,5-dimethylthiazol-2-yl)-2,5-diphenyltetrazolium bromide) tetrazolium assay was carried to detect the metabolic action of living cells using an MTT Cell Proliferation Assay (ATCC ${ }^{\circledR} 30-1010 \mathrm{~K}$ ) [29]. HEK 293 cells were seeded at a density of $1 \times 10^{4}$ cells per well containing $100 \mu \mathrm{L}$ medium in 96-well plates for $24 \mathrm{~h}$. The dried films (discs, number of replicates, $n=5$ in each case, with an average diameter of $3.735 \pm 0.46 \mathrm{~mm}$ and average thickness of $0.79 \pm 0.04 \mathrm{~mm}$ ) were soaked in RPMI 1640 media for softening before transferring to the wells and then they were incubated for $24 \mathrm{~h}$. After, $10 \mu \mathrm{L}$ of MTT reagent was added to each well, followed by incubation at $37^{\circ} \mathrm{C}$ in $5 \% \mathrm{CO}_{2}$ and $95 \%$ humidity for $4 \mathrm{~h}$. Subsequently, $100 \mu \mathrm{L}$ of detergent reagent (stop solution) was added to each well and placed in an incubator for $2 \mathrm{~h}$. Then, absorbance was recorded at $570 \mathrm{~nm}$ using a Synergy ${ }^{\mathrm{TM}}$ HTX Multi-Mode Microplate Reader (BioTek, Winooski, VT, USA). Cell viability was calculated as shown in Equation (1).

Cell viability $(\%)=($ mean absorbance of treated cells $/$ mean absorbance of control cells $) \times 100$

\subsection{Antimicrobial Activity (Zone of Inhibition)}

The antimicrobial activity of dried films of p(HEMA) and drugs-loaded p(HEMA) was determined using three different bacterial strains: S. aureus ATCC 6538, E. coli ATCC 8739, and P. aeruginosa ATCC 9027. The bacteria were thawed and incubated for $18 \mathrm{~h}$ at $37^{\circ} \mathrm{C}$ in an Erlenmeyer flask containing nutrient broth (NB). After $18 \mathrm{~h}$ bacteria were harvested by centrifugation and re-suspended in new NB until the optical density (OD $540 \mathrm{~nm}$ ) was equivalent to $1 \times 10^{8} \mathrm{CFU} \mathrm{mL}^{-1}$. The microorganisms were streaked on an MHA agar plate. Once the agar had set and cooled, discs of the drug-loaded hydrogels (diameter $5.58 \mathrm{~mm}$, thickness $0.79 \mathrm{~mm}$ ) were placed by sterile forceps on the surface of the inoculated MHA plates and incubated at $37^{\circ} \mathrm{C}$ for $18 \mathrm{~h}$. The diameter of the inhibition 
zone (clear zone indicating no bacterial growth) was measured daily for 14 days using a ruler caliber [28]. The experiment was set twice for each microorganism (at least 6 different discs were included in each experiment).

\subsection{Biofilm-Formation Ability}

The biofilm-formation ability was studied using $S$. aureus ATCC 6538, E. coli ATCC 8739, P. aeruginosa ATCC 9027, and a mixture of the 3 bacteria on dried films of p(HEMA), and drugs-loaded p(HEMA) surfaces (discs, number of replicates, $n=4$, with an average diameter of $3.74 \pm 0.46 \mathrm{~mm}$ and an average thickness of $0.79 \pm 0.04 \mathrm{~mm}$ ). Bacteria were incubated at $37^{\circ} \mathrm{C}$ for $18 \mathrm{~h}$ in NB. Then, they were harvested and re-suspended in heart infusion broth (HBI) with an OD $(540 \mathrm{~nm})$ of 0.3 , equivalent to $1 \times 10^{6} \mathrm{CFU} \mathrm{mL}^{-1}$. After $90 \mathrm{~min}$, non-attached bacteria were removed and fresh HBI was added. The plate was incubated at $37{ }^{\circ} \mathrm{C}$ for $24 \mathrm{~h}$ [30]. Then, the films were washed with sterile phosphatebuffered saline (PBS) and were incubated for $3 \mathrm{~h}$ with $150 \mu \mathrm{L}$ MTT. Then, $100 \mu \mathrm{L}$ of detergent reagent was added to each well and the plate was placed for $15 \mathrm{~min}$. The absorbance (OD) reading was performed at $570 \mathrm{~nm}$ using a Synergy ${ }^{\mathrm{TM}}$ HTX Multi-Mode Microplate Reader (BioTek, Winooski, VT, USA) [31].

\section{Results}

In this study, poly hydroxyethyl-methacrylate p(HEMA) was loaded with AMP, LVX, and different ratios of the drug combinations. The characterization of the dried films was carried out to determine the glass transition temperature $\left(\mathrm{T}_{g}\right)$, ultimate tensile strength (U.T.S.), elongation, and Young's modulus. An evaluation of cytotoxicity on HEK 293 cells to detect the metabolic action of living cells using an MTT Cell Proliferation Assay was also performed. In addition, various types of bacteria were used to determine the antimicrobial activity for 14 days. Finally, using an MTT assay, the monitoring of the biofilm-forming ability on different films surfaces was performed.

\subsection{Determination of Glass Transition Temperature}

The $\mathrm{T}_{g}$ value of $\mathrm{p}$ (HEMA) (control, F1) was similar to that of LVX-loaded $\mathrm{p}$ (HEMA) and 1:1 AMP:LVX-loaded p(HEMA), which were $130.97 \pm 2.11,131.91 \pm 0.69$, and 134.08 $\pm 0.63{ }^{\circ} \mathrm{C}$, respectively ( $p$-value $\left.>0.05\right)$. However, the addition of $0.5 \%(w / w)$ AMP to $\mathrm{p}$ (HEMA) decreased the $\mathrm{T}_{g}$ significantly, where it was $125.39 \pm 3.25{ }^{\circ} \mathrm{C}(p$-value $<0.0001)$. Moreover, the observations indicate that the use of different ratios of drug combinations resulted in the increase in $\mathrm{T}_{g}$ values as in (3:1) AMP: LVX- loaded $\mathrm{p}$ (HEMA) and (1:3) AMP: LVX- loaded p(HEMA), as shown in Figure 1.

\subsection{Mechanical Properties}

The effect of drugs on the tensile strength, Young's modulus, and the elongation percent of dried films is shown in Figure 2. The U.T.S. of p(HEMA) (control, F1) was identical to 1:1 AMP:LVX-loaded p(HEMA), which was $5.29 \pm 0.08$ and $5.38 \pm 0.01 \mathrm{~N} / \mathrm{mm}^{2}$, respectively ( $p$-value $>0.05)$. However, the addition of $0.5 \%(w / w)$ of AMP or LVX to $\mathrm{p}(\mathrm{HEMA})$ decreased the U.T.S. significantly, where it was $4.25 \pm 0.06 \mathrm{~N} / \mathrm{mm}^{2}(p$-value $<0.0001)$ and $4.96 \pm 0.12 \mathrm{~N} / \mathrm{mm}^{2}$ ( $p$-value $\left.=0.0003\right)$, respectively, compared to the control p(HEMA). Furthermore, the U.T.S. of different ratios of drug combinations increased in 3:1 AMP:LVXloaded p(HEMA) and 1:3 AMP:LVX- loaded p(HEMA). 


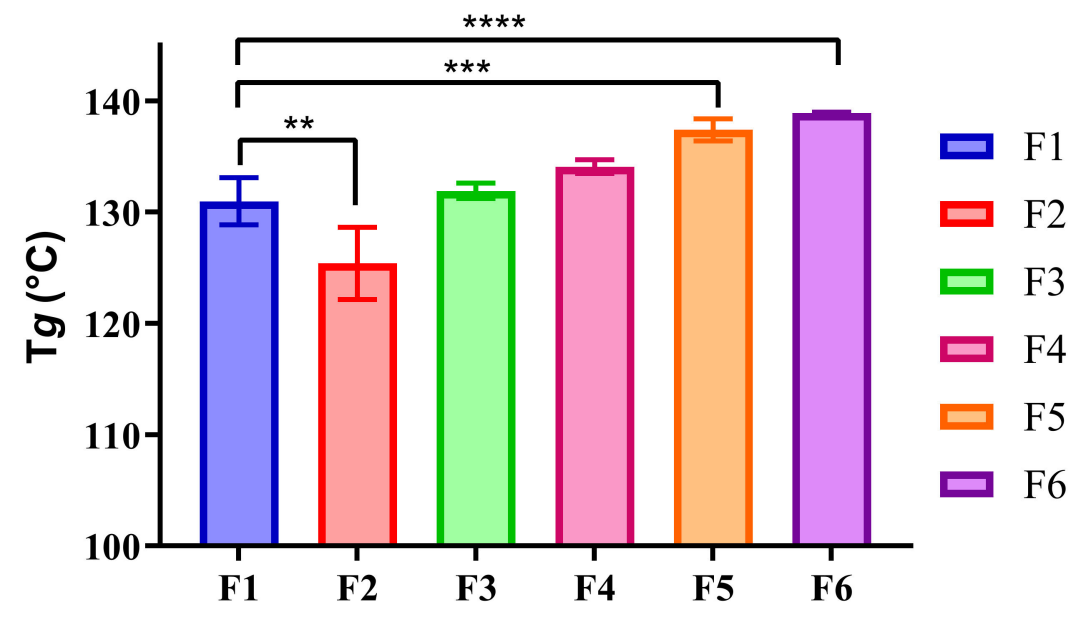

Formulations

Figure 1. The $\mathrm{T}_{g}$ of $\mathrm{p}(\mathrm{HEMA})$ (control (F1), F2, F3, F4, F5, and F6). Values present the average mean $\pm \mathrm{SD}, \mathrm{n}=3 .{ }^{* *} p<0.01,{ }^{* * *} p<0.001$, and ${ }^{* * *} p<0.0001$ significant difference between formulations.

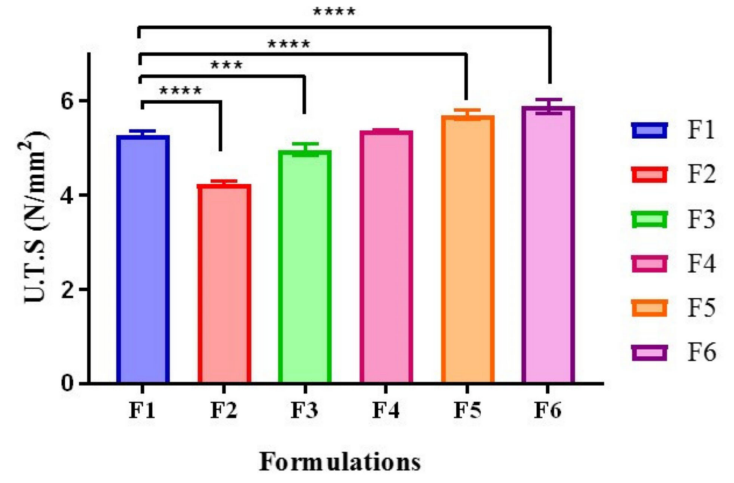

(a)

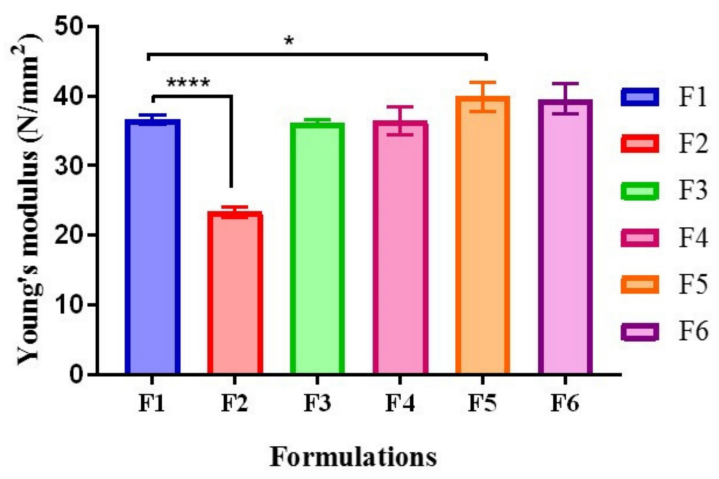

(b)

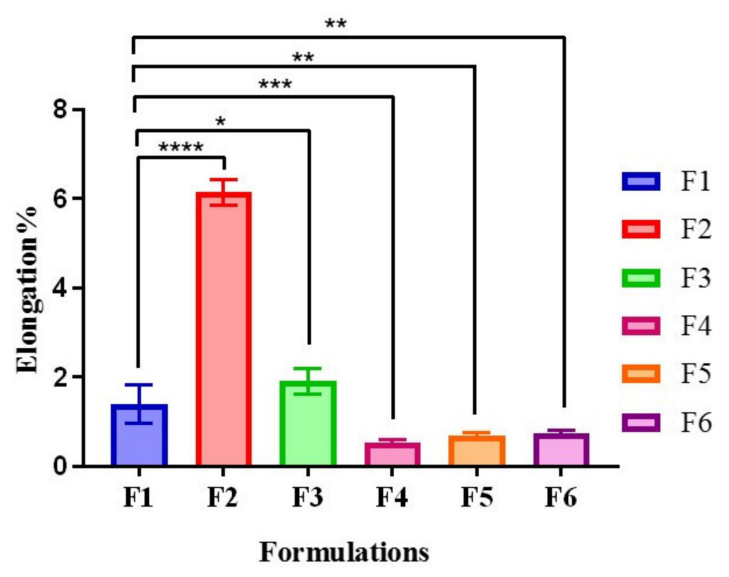

(c)

Figure 2. Mechanical properties of dried films of $\mathrm{p}$ (HEMA) and drugs-loaded $\mathrm{p}(\mathrm{HEMA})$ detected by Texture Analyzer. (a) U.T.S. N/ $\mathrm{mm}^{2}$, (b) Young's modulus $\left(\mathrm{N} / \mathrm{mm}^{2}\right.$ ) and (c) Elongation\%.: Values shown presenting average mean $\pm \mathrm{SD}$, $\mathrm{n}=3$. $^{*} p<0.05,{ }^{* *} p<0.01$, ${ }^{* * *} p<0.001$, and ${ }^{* * * *} p<0.0001$, a significant difference between formulations.

The Young's modulus of p(HEMA) (control, F1) was $36.60 \pm 0.61 \mathrm{~N} / \mathrm{mm}^{2}$. AMPloaded $\mathrm{p}(\mathrm{HEMA})$ significantly lowered the Young's modulus to $23.39 \pm 0.75 \mathrm{~N} / \mathrm{mm}^{2}$ 
( $p$-value $<0.0001)$. Moreover, the Young's modulus was significantly higher in 3:1 AMP:LVXloaded p(HEMA) than p(HEMA), which was $39.92 \pm 2.11 \mathrm{~N} / \mathrm{mm}^{2}(p$-value $<0.05)$. In the other dried films, the Young's modulus was similar to that of $\mathrm{p}$ (HEMA).

The elongation of p(HEMA) (control, F1) was $1.40 \% \pm 0.44 \%$, while the elongation of AMP-loaded p(HEMA) was significantly higher than that of the control p(HEMA), which was $6.14 \% \pm 0.29 \%$ ( $p$-value $<0.0001)$, as shown in Figure 2.

\subsection{Cytotoxity Evaluation of $p(H E M A)$ Hydrogel Formulations}

The cell viability of $\mathrm{p}$ (HEMA) (control, F1) was similar to that of F6, 1:3 AMP:LVXloaded p(HEMA) $(122.31 \% \pm 7.03 \%$ and $121.53 \% \pm 2.82 \%$, respectively, $p>0.05)$. However, in all tested films, the cell viability was higher than $80 \%$ [32], and thus was considered to be safe. As presented in Figure 3, HEK 293 cells are normal kidney cell used to test the safety of urological biomaterials [33].

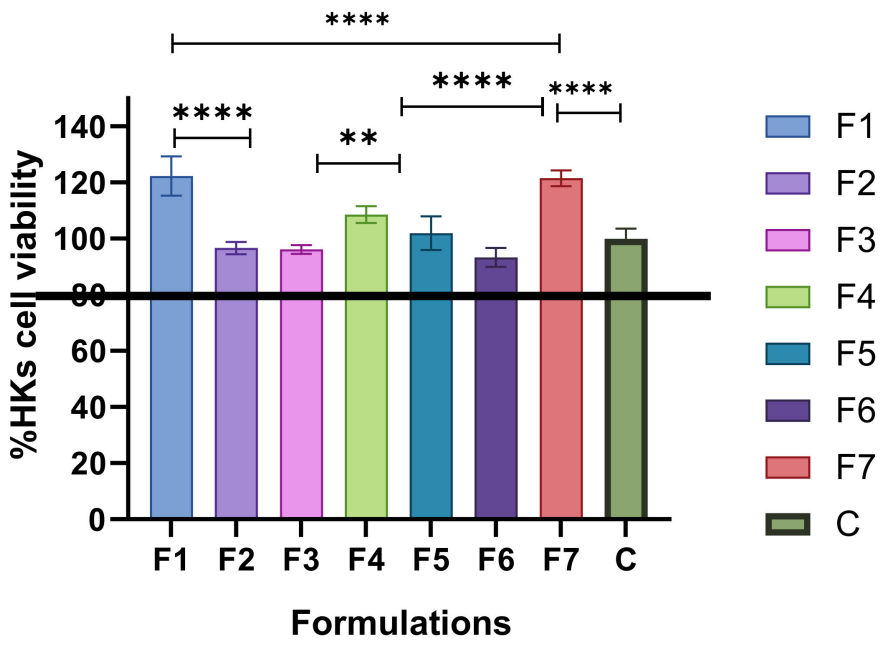

Figure 3. Cell viability of $\mathrm{p}(\mathrm{HEMA})$ hydrogel as control (C) and the drug -loaded hydrogels. Values shown represent the mean $\pm \mathrm{SD}, \mathrm{n}=5,{ }^{* *} p<0.01$, and ${ }^{* * *} p<0.0001$, significant difference between formulations. The black lines marks the $80 \%$ viability where less than $80 \%$ is considered toxic.

\subsection{Antimicrobial Activity (Zone of Inhibition)}

Dried films of AMP, LVX, and different ratios of drug combinations produced zones of inhibition against all tested bacteria, including Gram-positive bacteria such as S. aureus and Gram-negative bacteria such as E. coli and P. aeruginosa, as presented in Figure 4. In general, the size of the inhibition zone increased with time and remained for 14 days. An increase in the inhibition zone with time indicates that those materials would be suitable for long-term catheterization. Indwelling urological devices may be inserted for one day as an intermittent catheter and could be inserted for four months as stents. Thus, the inhibition zone was measured as a function of time. Upon loading p(HEMA) with AMP and LVX, the inhibition zone was influenced by the ratio used. A larger inhibition zone was observed in dried films of p(HEMA) impregnated with $0.5 \%$ ( $w / w)$ LVX (F3) and p(HEMA) impregnated with $0.125 \%: 0.375 \%(w / w)$ AMP: LVX (F6). This is reflected in the spectrum of activity of LVX [34]. The combined antimicrobial agents showed a larger inhibition zone at the initial time intervals compared with each antimicrobial agent alone.

\subsection{Biofilm-Formation Ability}

Biofilm-formation ability is classified according to the mean optical density value. A mean of optical density value above 0.2 indicates a strong biofilm-formation ability, $0.2 \geq$ OD $>0.1$ is considered moderate ability to form biofilm, $0.1 \geq \mathrm{OD}>0.05$ is classified as a weak ability to form biofilm, and OD $\leq 0.05$ indicates negative ability [35]. 


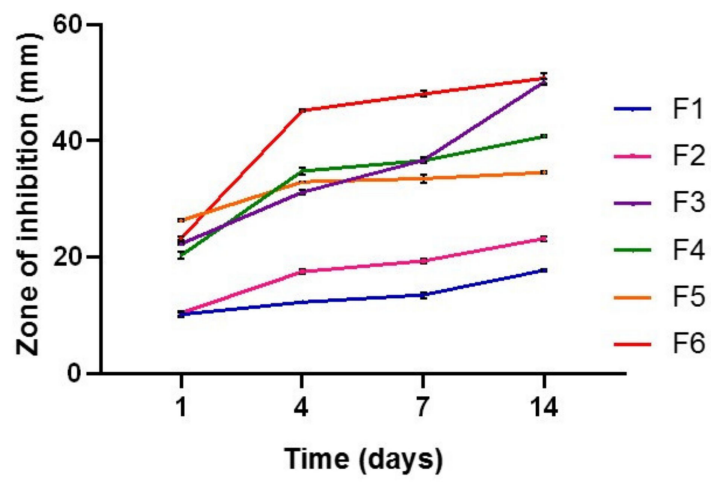

(a)

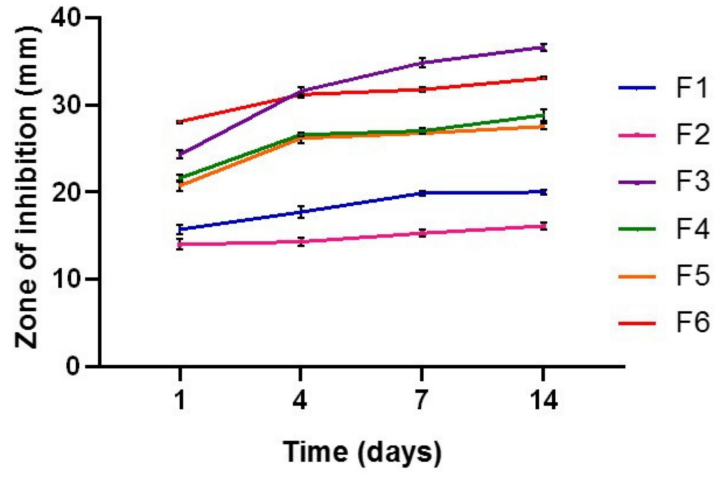

(b)

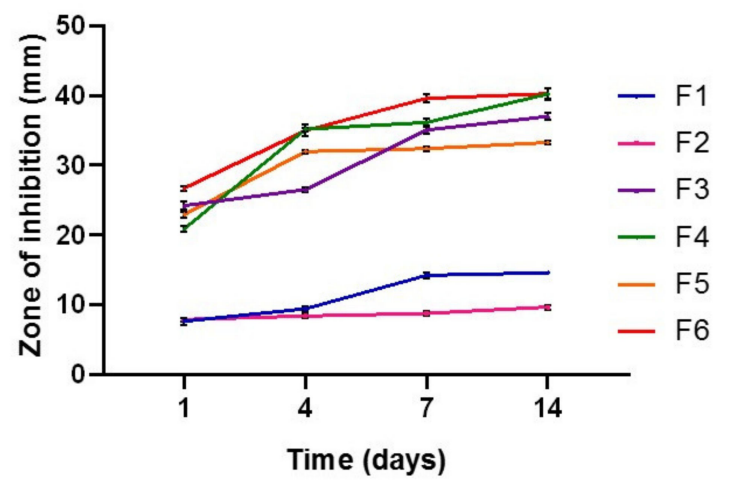

(c)

Figure 4. Zone of inhibition (mm) for p(HEMA) hydrogel as a control and the drug-loaded p(HEMA) hydrogel data represent at least 6 replicates in two independent experiments. (a) ZOI of S. aureus ( $\mathrm{n}=6 \pm$ S.D.), (b) ZOI of E. coli ( $\mathrm{n}=6 \pm$ S.D.), and (c) ZOI of P. aeruginosa ( $\mathrm{n}=6 \pm$ S.D.).

The biofilm-forming ability of $S$. aureus was similar on all dried film surfaces, whereas the biofilm-forming ability of $E$. coli decreased on the dried films except p(HEMA) and 1:3 AMP:LVX-loaded p(HEMA) (F6) surfaces. The biofilm-forming ability for P. aeruginosa increased on he $\mathrm{p}$ (HEMA) surface and reduced in $\mathrm{p}$ (HEMA) loaded with antimicrobial agents. Furthermore, the addition of LVX to the films reduced the mixed biofilm-forming ability. That is, the biofilm-forming ability of $S$. aureus on p-HEMA (control, F1) was $0.112 \pm 0.04$, AMP-loaded p(HEMA) (F2) was $0.23 \pm 0.21$, LVX-loaded p(HEMA) (F3) was $0.09 \pm 0.03,1: 1$ AMP:LVX-loaded p(HEMA) (F4) was 0.024 \pm 0.024, (3:1) AMP:LVX-loaded p(HEMA) (F5) was $0.009 \pm 0037$, and 1:3 AMP:LVX-loaded p(HEMA) (F6) was $0.073 \pm 0.054$. The biofilmforming ability of E. coli on p(HEMA) (control, F1) was $0.86 \pm 0.018$, F2 was $0.041 \pm 0.06$, $\mathrm{F} 3$ was $0.008 \pm 0.017, \mathrm{~F} 4$ was $0.099 \pm 0.08$, F5 was $0.009 \pm 0.12$, and F6 was $0.99 \pm 0.24$. The biofilm-forming ability of $P$. aeruginosa on p(HEMA) (control, F1) was $1.14 \pm 0.45, \mathrm{~F} 2$ was $0.046 \pm 0.057, \mathrm{~F} 3$ was $0.023 \pm 0.03, \mathrm{~F} 4$ was $0.023 \pm 0.07, \mathrm{~F} 5$ was $0.02 \pm 0.051$, F6 was $0.24 \pm 0.13$, and biofilm-forming ability of mixed biofilm on $\mathrm{p}$ (HEMA) (control, F1) showed overgrowth of bacteria, F2 was $2.27 \pm 0.83$, F3 was $0.032 \pm 0.017$, F4 was $0.032 \pm 0.016$, F5 was $0.29 \pm 0.38$, and F6 was $0.0026 \pm 0.116$.

\section{Discussion}

This study addressed the well-documented challenges of developing antimicrobial devices capable of resisting microbial growth and subsequent biofilm formation. The aforementioned challenge increases the financial burden on health care institutions because the only solution is to replace the infected device with a new one. Herein, a simple yet highly versatile technique was proposed to manufacture a material that is capable of delaying microbial growth and increasing the lifespan of a medical device. The synthesis of p(HEMA) hydrogel was carried out as described previously [24]. The hydrogel was 
loaded with two different antimicrobial agents, LVX and AMP, and a combination of both, using different ratios to evaluate their role in delaying the microbial contamination of the medical device. Characterization included determination of the $\mathrm{T}_{g}$, mechanical properties, determination of cytotoxicity, inhibition zone, and the ability to resist biofilm formation.

Transition temperature is a crucial indicators of several structural changes correlated with the chemical and physical behaviors of polymers. The $\mathrm{T}_{g}$ is a parameter that indicates the glassy to viscous liquid change, and it is correlated to polymer chain mobility and homogeneity as well as mechanical properties. The resulting DMTA thermogram showed one peak in all formulations. indicating that the hydrogel was homogeneous. The observed reduction in the $\mathrm{T}_{g}$ value of AMP-loaded $\mathrm{p}$ (HEMA) was attributed to the number of rotatable bonds in ampicillin, which implies that it enhanced the movement of the backbone chain. In addition, ampicillin trihydrate contains water in its structure, where the water decreased the $\mathrm{T}_{g}$ value [36]. The low $\mathrm{T}_{g}$ of $\mathrm{F} 2$ illustrates the low rigidity of the polymer, which explains the decrease in $\mathrm{T}_{g}$. The observed increase in $\mathrm{T}_{g}$ upon employing drug combinations can be attributed to drug-drug interaction, where an increase in the number of hydroxyl groups correlated strongly with $\mathrm{T}_{g}$ [37]. Attractive forces would increase the stiffness of the polymer backbone, and meaningless void volume would be obtained; thus, $\mathrm{T}_{g}$ would increase [38]. A direct influence of $\mathrm{T}_{g}$ is on mechanical properties, where increasing the $\mathrm{T}_{g}$ will lead to more flexible material, while a higher $\mathrm{T}_{g}$ implies a stiffer material with high Young's modulus and tensile strength values [38]. To improve patient tolerance, it is better to have flexible material; yet to maintain the function of a urinary catheter, the fabricated material should withstand a considerable amount of applied force. The demonstrated decrease in the U.T.S. and the increase in elongation of AMP-loaded p(HEMA) could be attributed to the higher number of rotatable bonds in ampicillin, which enhanced the movement of the backbone chain and decreased the $T_{g}$ value. Furthermore, the decrease in elongation and the increase in U.T.S. in different ratios of drug combinations were attributed to the increases in drug-drug and drug-polymer interactions. A higher film $\mathrm{T}_{g}$ indicates stronger attraction forces in the polymer backbone with the drugs and lower voidance volume $[38,39]$.

The employed films were safe and showed no toxicity on the tested cell culture (HEK 293), which originated from the kidneys, indicating that the interaction between the exemplar drugs and p(HEMA) hydrogel did not lead to the toxic effects on HEK 293 cells. This could be due to the hydrogel's ability to swell, allowing oxygen permeability. The cell viability was greater than $100 \%$, which is not unusual in the MTT assay [40], where utilizing a low concentration of treatment can lead to a higher cell viability, as observed in film formulations that contain low concentrations. The safety result implies that the fabricated biofilm is biocompatible.

The hydrogel formulations were fabricated in order to delay the microbial growth on the surface of the urinary devices; hence, it was crucial to determine the zone of inhibition over a prolonged period of time. The antimicrobial activity for $\mathrm{p}(\mathrm{HEMA})$ and drugs-loaded $\mathrm{p}$ (HEMA) persisted for 14 days. Loading $\mathrm{p}$ (HEMA) with a higher ratio of LVX alone or using the highest ratio of LVX ( $0.5 \%$ of LVX and loading p(HEMA) with $0.125 \%: 0.375 \%$ $(w / w)$ AMP: LVX (F6)) significantly increased antimicrobial activity. This was reflected in the spectrum of activity of LVX [34].

There are many microorganism species that can be involved in CAUTIs. Gram-positive bacteria such as $S$. aureus and Gram-negative bacteria such as E. coli and P. aeruginosa can adhere and form biofilms on catheter device surfaces. The biofilm is a complicated structure population of microbes that produces an extracellular polymeric matrix that is adherent on a surface [1]. Urinary biofilms are documented to be of mixed microbial species [2], which makes their treatment and management challenging. To detect the ability of $\mathrm{p}$ (HEMA) and drug-loaded $\mathrm{p}$ (HEMA) to withstand the conditions and resist biofilm formation, a test using an MTT kit was conducted to determine the metabolic activity of the adhered cells. The films were exposed to a mixed strain of common causative of CAUTIs for $3 \mathrm{~h}$, then treated properly to calculate the viable cells of the bacteria. The results showed that 
p(HEMA) alone without drug loading led to an enormous growth of microorganisms (Figure 5), which highlights the necessity of employing microbicides. Moreover, the use of LVX alone to load P(HEMA) in F3 and the use of a combination of LVX to AMP with high ratio of LVX in F6 were more capable of lowering the potential for biofilm formation. Employing antimicrobial agents to inhibit bacterial growth and biofilm-formation ability is a reasonable approach to both the prevention and treatment of infections [2]. p(HEMA) is a hydrophilic coating polymer with excellent antifouling capability due to the presence of the $\mathrm{O}-\mathrm{H}$ group in its structure [16]. Both Gram-positive and Gram-negative bacteria carry a negative charge on their surfaces, which led to initiating the repulsion between negatively charged bacteria and the negative charge of the $\mathrm{p}$ (HEMA) surface. The interaction between the bacteria and $\mathrm{p}$ (HEMA) surface decreased the biofilm-forming ability after loading $p$ (HEMA) with antimicrobial agents due to the antimicrobial action against bacteria. Both AMP and LVX act against Gram-positive and Gram-negative bacteria [12]. AMP acts as an irreversible inhibitor of the enzyme transpeptidase and thus inhibits cell wall synthesis and leads to cell lysis [41]. LVX inhibits bacterial deoxyribonucleic acid DNA gyrase, a type II topoisomerase [10].

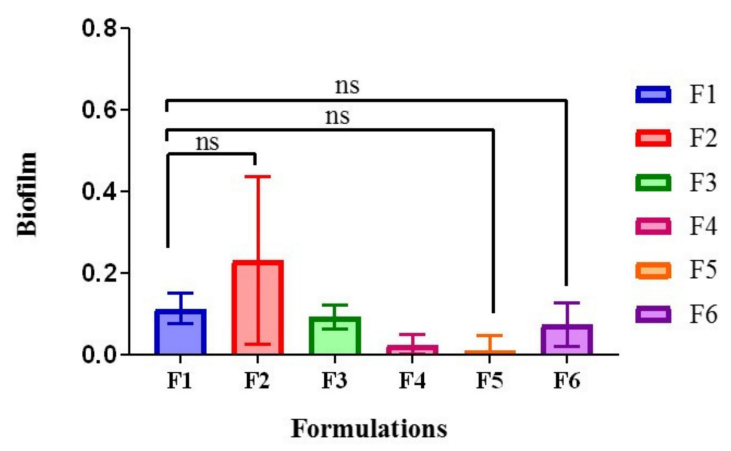

(a)

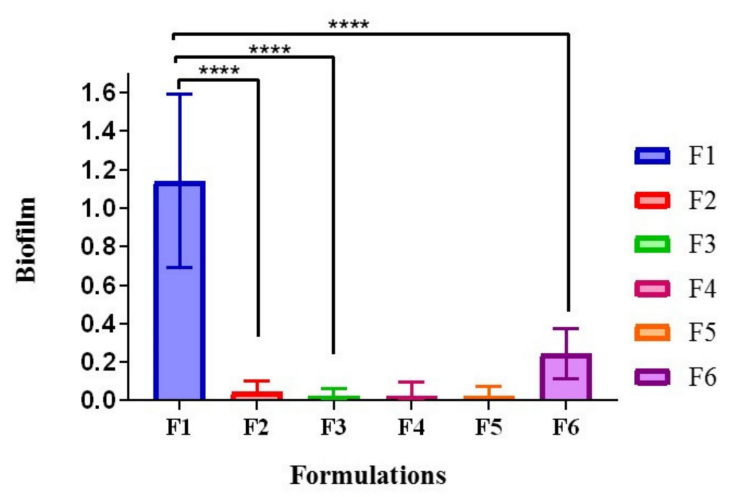

(c)

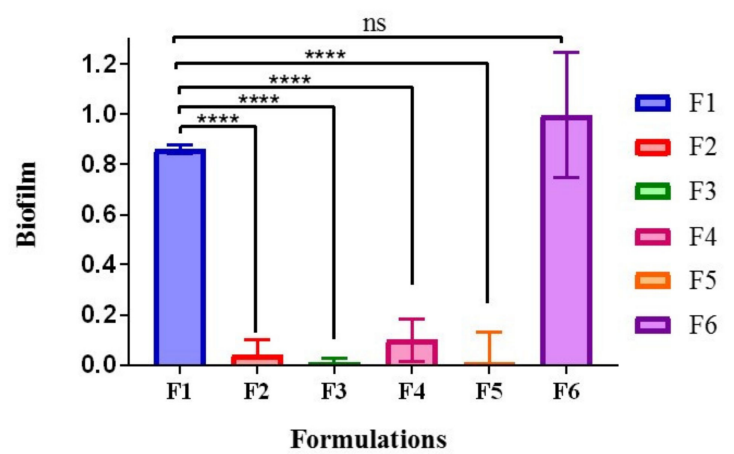

(b)

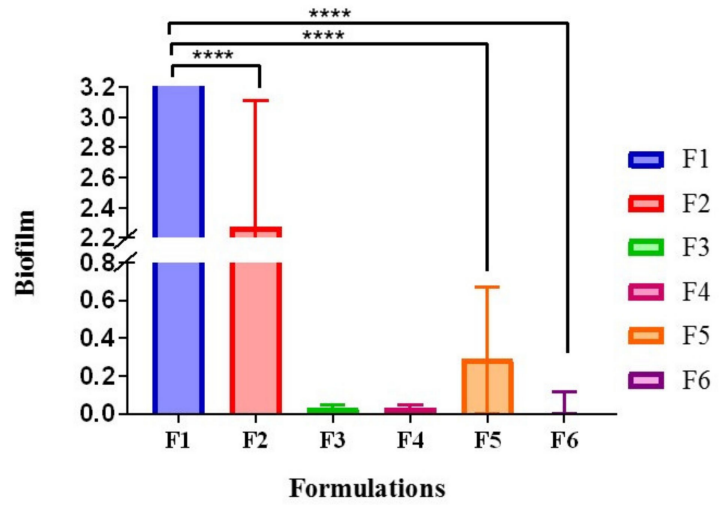

(d)

Figure 5. Biofilm-forming ability of $\mathrm{p}$ (HEMA) hydrogel formulations and drugs-loaded p(HEMA). (a) The biofilm-forming ability of $S$. aureus on p(HEMA) hydrogel formulations, (b) biofilm-forming ability of E. coli on p(HEMA) hydrogel formulations, (c) biofilm-forming ability of P. aeruginosa on p(HEMA) hydrogel formulations, and (d) biofilm-forming ability of mixed biofilm on $\mathrm{p}(\mathrm{HEMA})$ hydrogel formulations. Values represent the average mean $\pm \mathrm{SD}, \mathrm{n}=3^{* * * *} p<0.0001$, significant difference between formulations.

\section{Conclusions}

The employment of $\mathrm{p}(\mathrm{HEMA})$ in fabricating hydrogels for coating medical devices is an area of active research. Herein, $\mathrm{p}$ (HEMA) hydrogel was fabricated through a facile procedure, and impregnated with AMP and LVX and a combination of both microbicides in different formulations. The drugs affected both the thermal and mechanical properties of the hydrogel, where AMP lowered the $\mathrm{T}_{g}$ and increased the elongation, while LVX increased 
the $\mathrm{T}_{g}$ and increased stiffness. The antimicrobial and antibiofilm activity of the hydrogel showed that loading the polymeric hydrogel with drugs improved the antimicrobial and antibiofilm formation compared with using $\mathrm{p}$ (HEMA) alone. A significant reduction in the microbial growth and ability to biofilm formation was observed upon employing LVX alone or a combination of AMP and LVX with a higher load of LVX in favor of AMP and showed effects continuously for 14 days. The fabricated hydrogel can be employed in the field of urinary material and improve the lifespan for longer periods before replacement is necessary.

Author Contributions: Conceptualization, O.T.; methodology, O.T., W.A., L.H., L.A.A.-S., A.F.A., and H.A.-F.; software, W.A. and H.A.M.; formal analysis, H.A.M.; investigation, O.T.; resources, O.T.; data curation, W.A.; writing—original draft preparation, O.T.; writing-review and editing, L.H.; visualization, W.A.; supervision, O.T. and H.A.-F. project administration, O.T.; funding acquisition, O.T. All authors have read and agreed to the published version of the manuscript.

Funding: This research was funded by Al-Zaytoonah University of Jordan, grant number 27/12/2019-2020.

Institutional Review Board Statement: Not applicable.

Informed Consent Statement: Not applicable.

Data Availability Statement: All data are available in the manuscript.

Acknowledgments: The authors thank Colin McCoy from Queen's University of Belfast for his donation of the glass molds which were used in the synthesis of hydrogels.

Conflicts of Interest: The authors declare no conflict of interest.

\section{References}

1. Dehghanrad, F.; Nobakht-e-Ghalati, Z.; Zand, F.; Gholamzadeh, S.; Ghorbani, M.; Rosentha, V. Effect of instruction and implementation of a preventive urinary tract infection bundle on the incidence of catheter associated urinary tract infection in intensive care unit patients. Electron. J. Gen. Med. 2019, 16, em131. [CrossRef]

2. Shuman, E.K.; Chenoweth, C.E. Urinary Catheter-Associated Infections. Infect. Dis. Clin. 2018, 32, 885-897. [CrossRef] [PubMed]

3. Berne, C.; Ellison, C.K.; Ducret, A.; Brun, Y.V. Bacterial adhesion at the single-cell level. Nat. Rev. Microbiol. 2018, 16, 616-627. [CrossRef] [PubMed]

4. Ahmadabadi, H.Y.; Yua, K.; Kizhakkedathu, J.N. Surface modification approaches for prevention of implant associated infections. Colloids Surf. B Biointerfaces 2020, 193, 111116. [CrossRef]

5. Katoon, Z.; McTiernan, C.D.; Suuronen, E.J.; Mah, T.F.; Alarcon, E.I. Bacterial biofilm formation on implantable devices and approaches to its treatment and prevention. Heliyon 2018, 4, e01067. [CrossRef]

6. Li, Y.; Li, X.; Hao, Y.; Liu, Y.; Dong, Z.; Li, K. Biological and Physiochemical Methods of Biofilm Adhesion Resistance Control of Medical-Context Surface. Int. J. Biol. Sci. 2021, 17, 1769-1781. [CrossRef]

7. Zhu, Z.; Wang, Z.; Li, S.; Yuan, X. Antimicrobial strategies for urinary catheters. J. Biomed. Mater. Res. A 2018, 107, 445-467. [CrossRef]

8. Wu, H.; Moser, C.; Wang, H.Z.; Høiby, N.; Song, Z.J. Strategies for combating bacterial biofilm infections. Int. J. Oral Sci. 2015, 7, 1-7. [CrossRef]

9. Shah, K.J.; Cherabuddi, K.; Shultz, J.; Borgert, S.; Ramphal, R.; Klinker, K.P. Ampicillin for the treatment of complicated urinary tract infections caused by vancomycin-resistant Enterococcus spp (VRE): A single-center university hospital experience. Int. J. Antimicrob. Agents 2018, 51, 57-61. [CrossRef]

10. Wang, S.S.; Ratliff, P.D.; Judd, W.R. Retrospective review of ceftriaxone versus levofloxacin for treatment of E. coli urinary tract infections. Int. J. Clin. Pharm. 2018, 40, 143-149. [CrossRef]

11. Azargun, R.; Sadeghi, M.R.; Barhaghi, M.H.S.; Kafil, H.S.; Yeganeh, F.; Oskouee, M.A.; Ghotaslou, R. The prevalence of plasmidmediated quinolone resistance and ESBL-production in Enterobacteriaceae isolated from urinary tract infections. Infect. Drug Resist. 2018, 11, 1007-1014. [CrossRef]

12. Al-Soufi, W.F.; Al-Rekabi, F.M.K. Evaluating some biochemical parameters after repeated orally administration of levofloxacin in male rats. Res. J. Biotechnol. 2018, 12, 51-60.

13. Hu, L.; Zhang, Q.; Li, X.; Serpe, M.J. Stimuli-responsive polymers for sensing and actuation. Mater. Horiz. 2019, 6, 1774-1793. [CrossRef]

14. Hu, L.; Wan, Y.; Zhang, Q.; Serpe, M.J. Harnessing the Power of Stimuli-Responsive Polymers for Actuation. Adv. Funct. Mater. 2020, 30. [CrossRef]

15. Anirudhan, T.S.; Mohan, A.M. Novel pH sensitive dual drug loaded-gelatin methacrylate/methacrylic acid hydrogel for the controlled release of antibiotics. Int. J. Biol. Macromol. 2018, 110, 167-178. [CrossRef] 
16. Noferini, D.; Faraone, A.; Rossi, M.; Mamontov, E.; Fratini, E.; Baglion, P. Disentangling Polymer Network and Hydration Water Dynamics in Polyhydroxyethyl Methacrylate Physical and Chemical Hydrogel. J. Phys. Chem. C 2019, 123, 19183-19194. [CrossRef]

17. Pereira, A.T.; Henriques, P.C.; Costae, P.C.; Martins, M.C.L.; Magalhãesd, F.D.; Gonçalves, I.C. Graphene oxide-reinforced poly(2-hydroxyethyl methacrylate) hydrogels with extreme stiffness and high-strength. Compos. Sci. Technol. 2019, 184, 107819. [CrossRef]

18. Altındal, D.Ç.; Türkyılmaz, P.; Gümüşderelioğlu, M. P(HEMA)-based SPH vehicles for high molecular weight protein delivery. Int. J. Polym. Mater. 2020, 69, 773-785. [CrossRef]

19. Achilias, D.S.; Siafaka, P.I. Polymerization Kinetics of Poly (2 Hydroxyethyl Methacrylate) Hydrogels and Nanocomposite Materials. Processes 2017, 5, 21. [CrossRef]

20. Rossos, A.K.; Banti, C.N.; Kalampounias, A.G.; Papachristodoulou, C.; Kordatos, K.; Zoumpoulakis, P.; Mavromoustakos, T.; Kourkoumelis, N.; Hadjikakou, S.K. pHEMA@AGMNA-1: A novel material for the development of antibacterial contact lens. Mater. Sci. Eng. C 2020, 111, 110770. [CrossRef] [PubMed]

21. Arica, T.A.; Guzelgulgen, M.; Yildiz, A.A.; Demir, M.M. Electrospun GelMA fibers and p(HEMA) matrix composite for corneal tissue engineering. Mater. Sci. Eng. C 2021, 120, 111720. [CrossRef]

22. McCoy, C.P.; Irwin, N.J.; Donnelly, L.; Jones, D.S.; Hardy, J.G.; Carson, L. Anti-Adherent Biomaterials for Prevention of Catheter Biofouling. Int. J. Pharm. 2018, 535, 420-427. [CrossRef] [PubMed]

23. Ghanbaria, A.; Tabarsa, T.; Ashori, A.; Mashkour, M. Preparation and characterization of thermoplastic starch and cellulose nanofibers as green nanocomposites: Extrusion processing. Int. J. Biol. Macromol. 2018, 112, 442-447. [CrossRef] [PubMed]

24. Tarawneh, O.; Al-Assi, A.; Hamed, R.; Sunoqrot, S.; Hasan, L.; Al-Sheikh, I.; Naser, W. Development and characterization of k-carrageenan platforms as periodontal intra-pocket films. Trop. J. Pharm. Res. 2019, 18, 1791-1798. [CrossRef]

25. Liu, K.; Ostadhassan, M.; Bubach, B.; Dietrich, R.; Rasouli, V. Nano-dynamic mechanical analysis (nano-DMA) of creep behavior of shales: Bakken case study. J. Mater. Sci. 2018, 53, 4417-4432. [CrossRef]

26. Namini, A.S.; Asl, M.S.; Delbari, S.A. Influence of Sintering Temperature on Microstructure and Mechanical Properties of Ti-Mo-B ${ }_{4}$ C Composites. Met. Mater. Int. 2021, 27, 1092-1102. [CrossRef]

27. Bhat, A.; Smith, B.; Dinu, C.Z.; Guiseppi-Elie, A. Molecular engineering of poly(HEMA-co-PEGMA)-based hydrogels: Role of minor AEMA and DMAEMA inclusion. Mater. Sci. Eng. C. 2019, 98, 89-100. [CrossRef]

28. Grela, E.; Kozlowska, J.; Grabowiecka, A. Current methodology of MTT assay in bacteria-A review. Acta Histochem. 2018, 120, 303-311. [CrossRef] [PubMed]

29. Mourad, R.; Helaly, F.; Darwesh, O.; EL-Sawy, S. Antimicrobial and Physicomechanical Natures of Silver Nanoparticles Incorporated into Silicone-Hydrogel Films. Contact Lens Anterio 2019, 42, 325-333. [CrossRef] [PubMed]

30. Tan, Y.; Leonhard, M.; Schneider-stickler, B. Evaluation of Culture Conditions for Mixed Bio Fi Lm Formation with Clinically Isolated Non- Albicans Candida Species and Staphylococcus Epidermidis on Silicone. Microb. Pathog. 2017, 112, 215-220. [CrossRef] [PubMed]

31. Kong, L.; Rosli, F.N.; Chia, H.L.; Guan, J.; Pumera, M. Self-Propelled Autonomous Mg/Pt Janus Micromotor Interaction with Human Cells. Bull. Chem. Soc. Jpn. 2019, 92, 1754-1758. [CrossRef]

32. Horák, D.; Hlidková, H.; Klyuchivska, O.; Grytsyna, I. Applied Surface Science PEGylation Controls Attachment and Engulfment of Monodisperse Magnetic Poly ( 2-Hydroxyethyl Methacrylate ) Microspheres by Murine J774. 2 Macrophages. Appl. Surf. Sci. 2017, 426, 315-324. [CrossRef]

33. Werida, R.H.; El-Okaby, A.M.; El-Khodary, N.M. Evaluation of levofloxacin utilization in intensive care units of tertiary care hospital: A retrospective observational study. Drugs Ther. Perspect. 2020, 36, 33-39. [CrossRef]

34. Samadi, R.; Ghalavand, Z.; Nikmanesh, B.; Farahani, N.N.; Yasini, M.; Benvidi, M.E.; Eslami, G. Investigation of Biofilm Formation Among Methicillin-Resistant Staphylococcus Aureus Isolated from Children. Arch. Pediatr. Infect. Dis. 2018, 6. [CrossRef]

35. Qiao, C.; Ma, X.; Zhang, J.; Yao, J. Effect of hydration on water state, glass transition dynamics and crystalline structure in chitosan films. Carbohydr. Polym. 2019, 206, 602-608. [CrossRef]

36. Zhang, K.; Hanb, L.; Nie, Y.; Szigeti, M.L.; Ishida, H. Examining the effect of hydroxyl groups on the thermal properties of polybenzoxazines: Using molecular design and Monte Carlo simulation. RSC Adv. 2018, 8, 18038-18050. [CrossRef]

37. SheinbaumL, M.; Sheinbaum, L.; Weizman, O.; Dodiuk, H.; Kenig, S. Toughening and enhancing mechanical and thermal properties of adhesives and glass-fiber-reinforced epoxy composites by brominated epoxy. Compos. B Eng. 2019, 15, 604-612. [CrossRef]

38. Ma, X.; Zheng, F.; Lu, Q. Role of Intrinsic Factors of Polyimides in Glass Transition Temperature: An Atomistic Investigation. J. Phys. Chem. B 2019, 123, 8569-8579. [CrossRef]

39. Emter, R.; Natsch, A. A Fast Resazurin-Based Live Viability Assay Is Equivalent to the MTT-Test in the KeratinoSens Assay. Toxicol. Vitr. 2015, 29, 688-693. [CrossRef] [PubMed]

40. Laskowski, D.; Strzelecki, J.; Pawlak, K.; Dahm, H.; Balter, A. Effect of ampicillin on adhesive properties of bacteria examined by atomic force microscopy. Micron 2018, 112, 84-90. [CrossRef]

41. El-Baky, R.M.A.; Sandle, T.; John, J.; Abuo-Rhma, G.E.A.A.; Hetta, H.F. A novel mechanism of action of ketoconazole: Inhibition of the NorA efflux pump system and biofilm formation in multidrug-resistant Staphylococcus aureus. Infect. Drug Resist. 2019, 12, 1703-1718. [CrossRef] [PubMed] 